\title{
A Novel Rearrangement of Fluorescent Human Thymidylate Synthase Inhibitor Analogues in ESI Tandem Mass Spectrometry
}

\author{
Yi Chen, ${ }^{\text {a }}$ Céline Le Droumaguet, ${ }^{\mathrm{a}} \mathrm{Kai} \mathrm{Li}^{\mathrm{b}}{ }^{\mathrm{b}}$ William E. Cotham, ${ }^{\mathrm{a}}$ \\ Norman Lee, ${ }^{\mathrm{c}}$ Mike Walla, ${ }^{\mathrm{a}}$ and Qian Wang ${ }^{\mathrm{a}}$ \\ ${ }^{a}$ Department of Chemistry and Biochemistry, University of South Carolina, Columbia, South Caroline, USA \\ b State Key Laboratory of Fine Chemicals, Dalian University of Technology (DUT), Dalian, People's Republic \\ of China \\ ${ }^{\text {c }}$ FAS Center for Systems Biology Mass Spectrometry and Proteomics Laboratory, Harvard University, \\ Cambridge, Massachusetts, USA
}

$\mathrm{Cu}(\mathrm{I})$ catalyzed alkyne-azide cycloaddition reaction was employed to synthesize a series of anthracene-based human thymidylate synthase (hTS) inhibitor analogues. The triazoloanthracene derivatives were characterized by ESI-MS/MS and a novel rearrangement reaction in ESI-MS/MS was observed. The mechanism is proposed whereby the protonated triazoloanthracene derivative forms a carbocation, and then the carbocation electrophilically attacks an anthracene moiety resulting in formation of a rearrangement ion. Moreover, the carbocation prefers to attack the $\gamma$ position rather than the $\alpha$ or $\beta$ position of the anthracene moiety by an electrophilic substitution mechanism. (J Am Soc Mass Spectrom 2010, 21, 403-410) () 2010 American Society for Mass Spectrometry

$\mathrm{H}$ uman thymidylate synthase (hTS) has been targeted in cancer therapy for many years [1]. The catalytic mechanism of this enzyme is very complicated and some of its biochemical properties, such as subunit cooperativity and conformational switching, remain to be elucidated [2]. Recent findings suggest that the intracellular localization of hTS has certain correlations with cancer malignancy [3]. Therefore, developing fluorescently labeled inhibitors as probes, which would bind to hTS to monitor its intracellular expression and localization as a function of cell cycle, is significant for elucidating the role of hTS and its involvement in tumorigenesis. Our efforts focus on using $\mathrm{Cu}(\mathrm{I})$ catalyzed alkyne-azide cycloaddition (CuAAC) reaction [4-10] to synthesize a library of fluorescent hTS probes, which can also behave as potential inhibitors.

Mass spectrometry (MS) is an indispensable tool for analysis of small molecules, peptides, and proteins. In particular, collision induced dissociation (CID) has unique advantages in elucidating the structural features of compounds and studying the mechanism of rearrangement reactions in mass spectrometry by providing detailed fragmentation data [11-13]. Some investigations on rearrangement reactions occurring in electrospray ionization tandem mass spectrometry (ESI-MS/ MS), such as carbonyl oxygen migration, amino group migration, $\mathrm{P}-\mathrm{N}$ to $\mathrm{P}-\mathrm{O}$ rearrangement, formamide ex-

Address reprint requests to Dr. Q. Wang, Department of Chemistry and Biochemistry, 631 Sumter St., Columbia, SC 29208, USA. E-mail: wang@ mail.chem.sc.edu trusion, methoxy group migration, carbocation rearrangement, etc. have been published [14-20]. Herein, we report the characterization of triazolo-anthracene derivatives as hTS inhibitor analogues, and particularly, a rearrangement reaction of triazolo-anthracene derivatives discovered in ESI-MS/MS. The systematic investigation of these triazolo-anthracene derivatives and their corresponding fragmentations are not only necessary for further developing potential fluorescent hTS inhibitors as fluorescent probes but also for enriching methodological research in mass spectrometry.

\section{Experimental}

\section{Chemical Materials}

All triazolo-anthracene derivatives were synthesized in our laboratory. The starting materials for synthesis were purchased from VWR (Suwanee, GA, USA) or Sigma (St. Louis, MO, USA). ${ }^{1} \mathrm{H}$ NMR and ${ }^{13} \mathrm{C}$ NMR spectra were recorded on Varian 300 NMR spectrometer. Azidomethylanthracenes, Z1, Z2, and Z3, and 3-ethynylquinoline $\mathbf{A} 2$ have previously been described in the literature [5, 21, 22]. Compounds A1, A5, A6, and A9 have been prepared by reaction between propargyl bromide and the corresponding amines or alcohols under basic conditions. Compounds A3, A4, A8, A10, and $\mathbf{A} 7$ were obtained from nucleophilic substitution between the corresponding brominated compounds and 3-phenylpropargylamine and tert-butyl 4-aminobenzoate, respectively. 


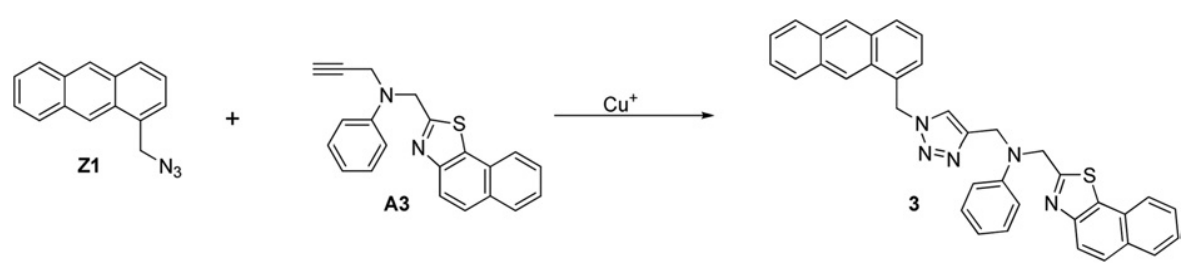

Scheme 1. Synthesis of Compound 3 via cycloaddition (CuAAC) reaction of $\mathbf{Z 1}$ and $\mathbf{A} 3$.

\section{General Protocol of CUAAC Reaction for the Synthesis of Triazolo-Anthracene Derivatives}

To a solution of 1-(azidomethyl)anthracene $\mathbf{Z 1}(60 \mathrm{mg}$, $257 \mu \mathrm{mol}) \mathrm{N}$-(naphtho[2,1-d]thiazol-2-ylmethyl)- $\mathrm{N}$-(prop2-ynyl)aniline $\mathbf{A 3}(84 \mathrm{mg}, 257 \mu \mathrm{mol})$ in a 3:1 mixture (vol/vol) of $\mathrm{DMF} / \mathrm{H}_{2} \mathrm{O}(24 \mathrm{~mL})$ were added with $\mathrm{CuSO}_{4}(10 \mathrm{mg}, 39 \mu \mathrm{mol})$, sodium ascorbate $(15 \mathrm{mg}, 77$ $\mu \mathrm{mol})$, and tris(thiazolyl)benzylamine ( $7 \mathrm{mg}, 13 \mu \mathrm{mol})$ (shown in Scheme 1). The mixture was stirred at RT for 15 h. After extraction with EtOAc, the organic layers were washed with water, dried over $\mathrm{MgSO}_{4}$, and the solvents were evaporated. The crude product was then purified by column chromatography $\left(\mathrm{CH}_{2} \mathrm{Cl}_{2} / \mathrm{EtOAc}\right.$ gradient from 90:10 to 80:20) to yield $102 \mathrm{mg}$ (71\%) of Compound 3: Compound 3 was identified by ${ }^{1} \mathrm{H}$ NMR and ESI-MS/MS and high-resolution ESI-MS/MS as follows: ${ }^{1} \mathrm{H}$ NMR $\left(300.11 \mathrm{MHz}, \mathrm{CDCl}_{3}\right): \delta 8.34(\mathrm{~s}, 1 \mathrm{H})$, $8.29(\mathrm{~s}, 1 \mathrm{H}), 7.91-7.69(\mathrm{~m}, 7 \mathrm{H}), 7.47-7.36(\mathrm{~m}, 4 \mathrm{H})$, 7.31-7.19 (m, $3 \mathrm{H}), 7.07-7.02(\mathrm{~m}, 2 \mathrm{H}), 6.77(\mathrm{~d}, J=7.8$ $\mathrm{Hz}, 2 \mathrm{H}), 6.66(\mathrm{t}, J=7.3 \mathrm{~Hz}, 1 \mathrm{H}), 5.97(\mathrm{~s}, 2 \mathrm{H}), 4.80$ (s, $2 \mathrm{H}), 4.71(\mathrm{~s}, 2 \mathrm{H}) ;{ }^{13} \mathrm{C}$ NMR $\left(75.47 \mathrm{MHz}, \mathrm{CDCl}_{3}\right)$ : $\delta=171.5,151.7,147.8,145.5,132.3,132.2,132.9,131.8$, $131.1,130.6,130.0,129.5,129.2,129.1,128.8,128.3,128.0$, $127.7,127.4,127.3,127.1,126.3,126.1,125.3,124.6,122.4$, $121.9,119.1,114.3,54.4,53.0,48.1$; the observed mass of protonated Compound 3 by high-resolution ESIMS/MS is mass of 562.2065 (calculated mass 562.2060). All triazolo-anthracenes (1-12) were synthesized by the same method using appropriate Compound (Z1-Z3) and Compound (A1-A10) (Table 1).

\section{Mass Spectrometry}

The MS/MS mass spectra were acquired in the positive ion mode by a Micromass QTOF (Waters, Milford, MA, USA) equipped with an electrospray source. The source temperature was held constant at $80^{\circ} \mathrm{C}$. The desolvation temperature was set at $300^{\circ} \mathrm{C}$. The capillary voltage was $4 \mathrm{kV}$. Full scan spectra were collected from $\mathrm{m} / \mathrm{z}$ 100 to 1000. The collision energy in the collision cell was set at 23-25 V for MS/MS. MassLynx 4.0 (Waters, Milford, MA, USA) was used for data acquisition and analysis. The high-resolution MS/MS data were also acquired by Micromass QTOF instrument with resolution of 7500 FWHM. The calibration for high-resolution MS/MS was achieved as follows: (1) Initial calibration was achieved with a solution of sodium trifluoroacetate (TFA) (50-100 mM), which gives ions across a wide mass range. (2) The TFA cluster ion at mass of 566.8890 was used as lock mass for parent ion. (3) For accurate mass analysis of rearrangement ion in MS/MS mode, the parent ion was used for the lock mass. The average mass accuracy of the measurements for rearrangement ion (388.1176) was achieved by averaging six experimental data $(388.1194 ; 388.1182 ; 388.1152 ; 388.1161 ; 388.1197$, and 388.1171).

\section{Calculations}

All energies (E) for methane, methyl carbocation, Compound 3, and Compound 4 were evaluated at the B3LYP /6-31G* level using Spartan'06 software (Irvine, CA, USA). The stabilization energies (SE) for Compounds 3 and 4 are calculated using an isodesmic equation as follows [23].

$$
\begin{aligned}
\mathrm{SE}= & \mathrm{E}_{\text {alkane }}+\mathrm{E}_{\text {carbocation }}-\mathrm{E}_{\text {carbocation1 }} \\
& -\mathrm{E}_{\text {methane }}(\mathrm{Kcal} / \mathrm{mol})
\end{aligned}
$$

The Mulliken charge on atoms and condensed Fukui index values of intermediate 3-IIb from Compound 3 were obtained at the DFT B3LYP level of theory with a 6-31G* basis set with Spartan'06 software. All the calculations were based on equilibrium geometry calculation by searching for a stationary point. In addition, we tested the final geometry by calculating the vibration frequencies and verifying all frequencies that are positive. It indicates that all the carbocations are at minimaenergy geometries.

\section{Results and Discussion}

\section{Fragmentation Pathways of Compound 3}

A series of fluorescent hTS inhibitor analogues (triazoloanthracene derivatives) were synthesized by copper (I)-catalyzed alkyne-azide cycloaddition (Scheme $\mathbf{1}$ and Table 1) and the structures were characterized by ESIMS/MS (Table 3). The MS/MS mass spectrum of Compound 3 (Figure 1a) shows four expected peaks at $\mathrm{m} / \mathrm{z}$ $191,198,244,562$, and one unexpected peak at $\mathrm{m} / \mathrm{z} 388$. According to the molecular formula $\mathrm{C}_{36} \mathrm{H}_{27} \mathrm{~N}_{5} \mathrm{~S}$, the peak at $\mathrm{m} / z 562$ corresponds to the protonated molecule. The base peak at $m / z 191$ is produced by the cleavage of the $\mathrm{C}-\mathrm{N}$ bond between the anthracene moiety and the triazole moiety. The $\pi$-system on anthracene moiety enhances the thermodynamic stability of the carbocation resulting in the base peak in the MS/MS spectrum. 
Table 1. Structures of starting azides, alkynes and corresponding products

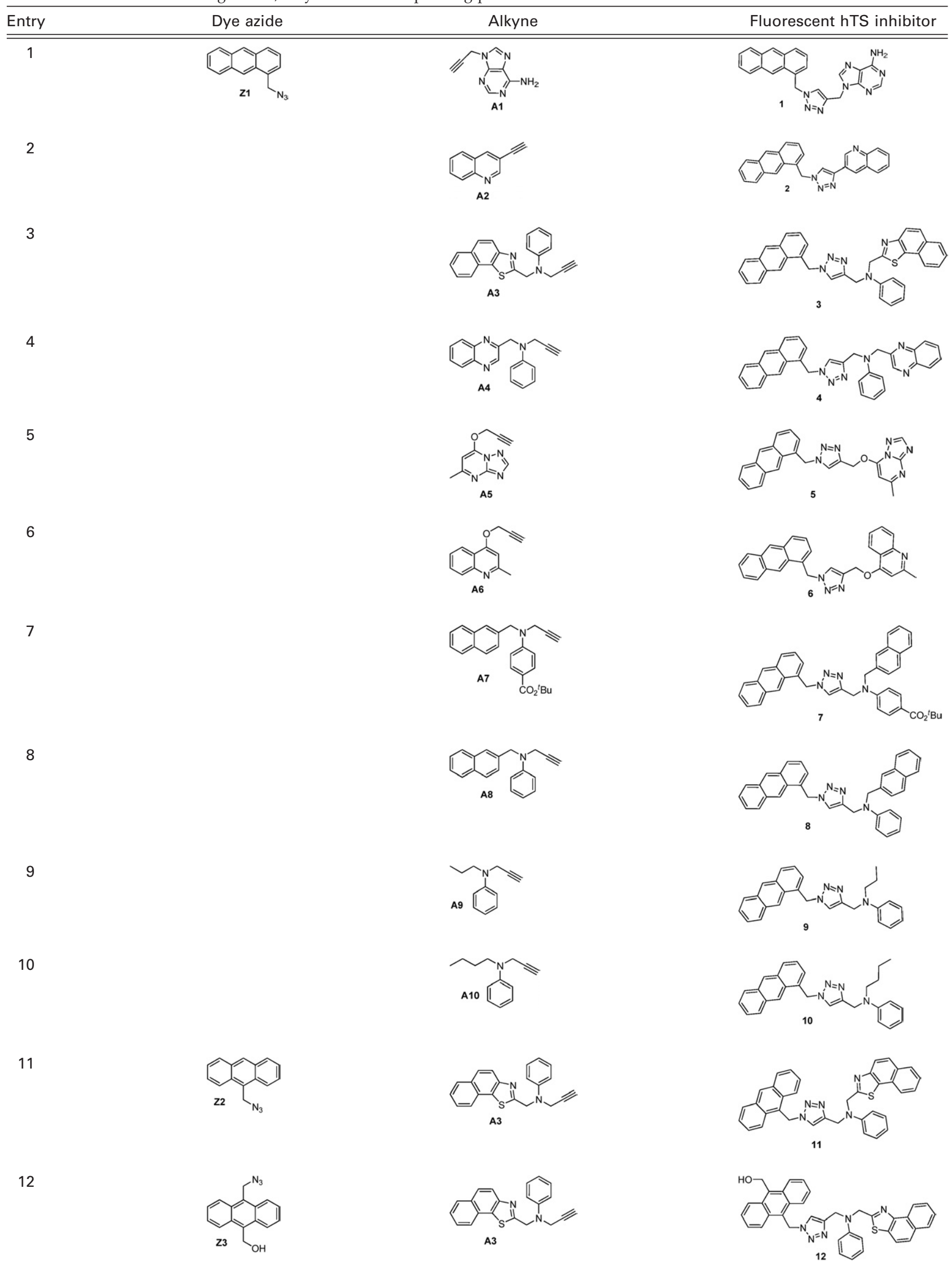


Table 2. Accurate masses of protonated Compound 3 and its rearrangement ion at $\mathrm{m} / \mathrm{z} 388$

\begin{tabular}{lcccc}
\hline \multicolumn{1}{c}{ Ion } & Elemental composition & Accurate mass (calculated) & Observed mass & Relative error (ppm) \\
\hline \hline Protonated Compound 3 & $\mathrm{C}_{36} \mathrm{H}_{28} \mathrm{~N}_{5} \mathrm{~S}^{+}$ & 562.2060 & 562.2065 & 0.9 \\
Rearrangement ion at $\mathrm{m} / \mathrm{z} 388$ & $\mathrm{C}_{27} \mathrm{H}_{18} \mathrm{NS}^{+}$ & 388.1160 & 388.1176 & 4.1 \\
\hline
\end{tabular}

Apart from the base peak and the peak of protonated molecule, a couple of peaks at $\mathrm{m} / \mathrm{z} 244$ and 198 that resulted from the heterolytic cleavage of $\mathrm{C}-\mathrm{N}$ bonds on both sides of the protonated tertiary amine can be clearly observed. The ion at $\mathrm{m} / \mathrm{z} 244$ is the result of the neutral loss of $\mathrm{N}_{2}$ from the triazole moiety and the cleavage of the $\mathrm{C}-\mathrm{N}$ bond [24]. The peak at $\mathrm{m} / \mathrm{z} 198$ is attributed to the cleavage of another $\mathrm{C}-\mathrm{N}$ bond on the tertiary amine group, which plays a significant role in the subsequent rearrangement reaction. The MS/MS fragmentation pathways of Compound $\mathbf{3}$ as an example of triazolo-anthracene derivatives in positive mode ESIMS/MS are summarized in Scheme 2.

\section{Rearrangement Mechanism of Compound 3}

The peak at $m / z 388$ observed in Figure 1a, which is unlikely to arise from any moiety, could not be explained by a simple fragmentation pathway. Moreover, similar fragment ions were not observed in the other triazolo-anthracene derivatives, such as Compounds $\mathbf{1}$ and 2 (Table 1 and Table 3). A possible explanation for this peak at $m / z 388$ is that an intramolecular rearrangement reaction occurs in ESI-MS/MS. To rationalize this observation, a novel rearrangement mechanism is proposed here that the rearrangement reaction may occur along the pathways as shown in Scheme 3. The rearrangement proceeds with the protonation of the tertiary amine (3-I) and breaking of the $\mathrm{N}-\mathrm{C}$ bond resulting in the formation of a carbocation (3-IIa) at $\mathrm{m} / \mathrm{z}$ 198, which corresponds to the peak at $\mathrm{m} / \mathrm{z} 198$ (Figure 1a). The carbocation may further form a weakly associated $\pi$-carbocation complex (3-IIa-3-IIb) with the anthracene moiety. The electrophilic attack of this carbocation (3-IIa) on the anthracene moiety (3-IIb) would lead to the transition-state (3-III). The nitrogen atom on the triazole moiety donates its lone pair of electrons to accept the proton, leading to migration of the proton to the nitrogen atom. The two electrons move into the anthracene moiety to reform the $\pi$ bond and recover the aromatic system, thus neutralizing the positive charge on the carbon to form (3-IV). Finally, the cleavage of the $\mathrm{C}-\mathrm{N}$ bond between the anthracene moiety and the triazole moiety results in the final rearrangement ion at $m / z 388(3-\mathbf{V})$.

\section{Elemental Composition Analysis}

To further examine the elemental composition of the rearrangement ion at $\mathrm{m} / \mathrm{z} 388$, Compound 3 and its rearrangement ion were analyzed by high-resolution ESI-MS/MS. Table 2 and Figure 2 show their corresponding elemental compositions, calculated and observed masses, and relative errors. Since the relative errors are less than 5ppm, these results suggest that the elemental compositions of both protonated Compound 3 and its rearrangement ion, which are proposed in the rearrangement mechanism, are consistent with the experimental values.

\section{Analysis of Analogous Compounds by MS/MS}

Based on the proposed rearrangement mechanism, two key factors are crucial in the rearrangement process. One is the formation of a stable carbocation and the other is the position attacked by the carbocation on the anthracene moiety. Compounds 7, 8, and 4 (Table 1), which are believed to form similar carbocations, were synthesized and fragmented under the same MS/MS conditions. The rearrangement ions were also observed in the MS/MS spectra (Figure 1b, c, and d). These results show that all these compounds are likely to undergo similar rearrangement reactions via a carbocation formation, electrophilic attack, and migration of the carbocation.

Table 3. Major fragment ions in ESI-MS/MS

\begin{tabular}{|c|c|c|c|c|c|c|c|}
\hline \multirow[b]{2}{*}{ No. } & \multirow[b]{2}{*}{ Compound } & \multirow[b]{2}{*}[\mathrm{M}+\mathrm{H}]{$^{+} \mathrm{m} / \mathrm{z}$} & \multirow{2}{*}{$\begin{array}{l}\text { Rearrangement } \\
\text { ion } m / z\end{array}$} & \multicolumn{4}{|c|}{ Fragment ions $\mathrm{m} / \mathrm{z}$ (relative intensity $\%$ ) } \\
\hline & & & & a & b & c & $d$ \\
\hline 1 & 1 & $407(21)$ & - & & $244(25)$ & $191(100)$ & $136(92)$ \\
\hline 2 & 2 & $387(8)$ & - & 359 (11) & - & $191(92)$ & - \\
\hline 3 & 3 & $562(8)$ & $388(8)$ & & $244(3)$ & $191(100)$ & $198(5)$ \\
\hline 4 & 4 & $507(22)$ & 333 & & $244(4)$ & $191(100)$ & - \\
\hline 5 & 5 & $422(2)$ & - & & $244(28)$ & $191(100)$ & $151(8)$ \\
\hline 6 & 6 & $431(0)$ & - & $403(17)$ & $244(24)$ & $191(140)$ & $160(100)$ \\
\hline 7 & 7 & 505 (4) & 331 (1) & & $244(1)$ & $191(100)$ & 141 (4) \\
\hline 8 & 8 & $605(9)$ & 331 (2) & & - & $191(100)$ & $141(4)$ \\
\hline 9 & 9 & 407 (11) & - & & $244(3)$ & $191(100)$ & \\
\hline 10 & 10 & 421 (13) & - & & $244(5)$ & $191(100)$ & \\
\hline 11 & 11 & $562(7)$ & $388(1)$ & & - & $191(100)$ & - \\
\hline
\end{tabular}



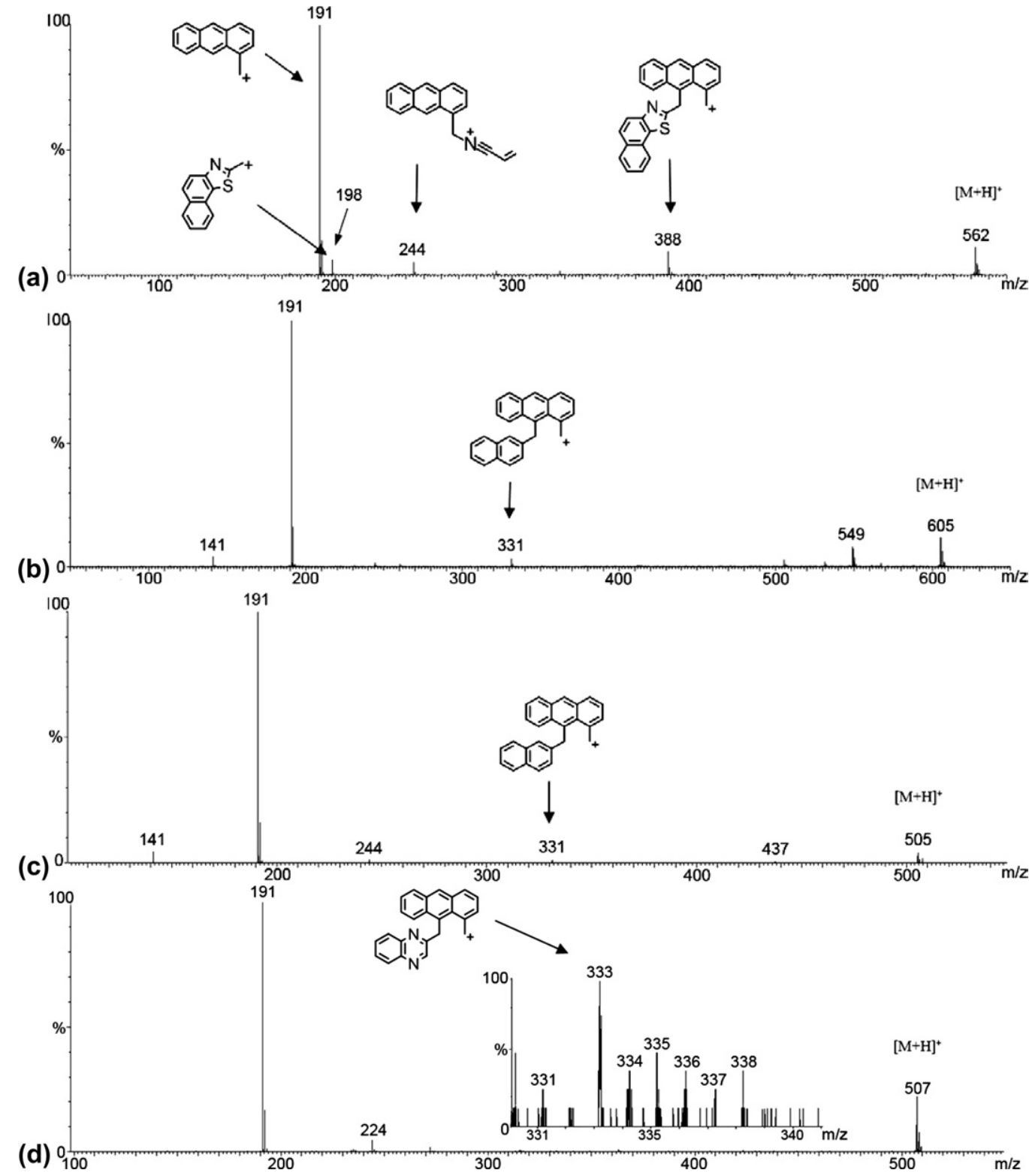

Figure 1. MS/MS spectra of Compounds 3 (a), 7 (b), 8 (c), and 4 (d).

However, the abundance of the rearrangement ion for these various compounds varies considerably in MS/MS. Among these compounds, Compound 3 gives the most abundance from the rearrangement ion, while the abun-

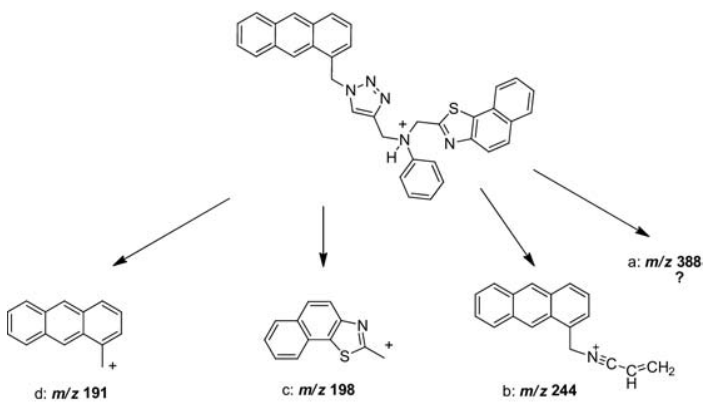

Scheme 2. Fragmentation pathways of Compound 3. dance of the rearrangement ion from Compound 4 is very low. This difference may be attributed to the stability of the carbocation. Among Compounds 3, 4, 7, and 8, Compound 3 likely has the most stable resonance structure because the positive charge can be delocalized and distributed on the sulfur atom by resonance to afford a much more stable sulfonium ion-like resonance structure. In addition, the non-bonding electrons of the sulfur may also make a contribution to stabilize the positive charge due to the spatial proximity. As a comparison, the carbocation of Compound 4 lacks either of these stabilization contributions. Therefore, the rearrangement reaction of Compound 4 is less favorable, resulting in very low abundance produced by the rearrangement ion derived from Compound 4 in the MS/MS spectrum.

The stabilization energies of carbocations for Compound 3 (90.6807 kcal/mol) and Compound 4 (74.8317 


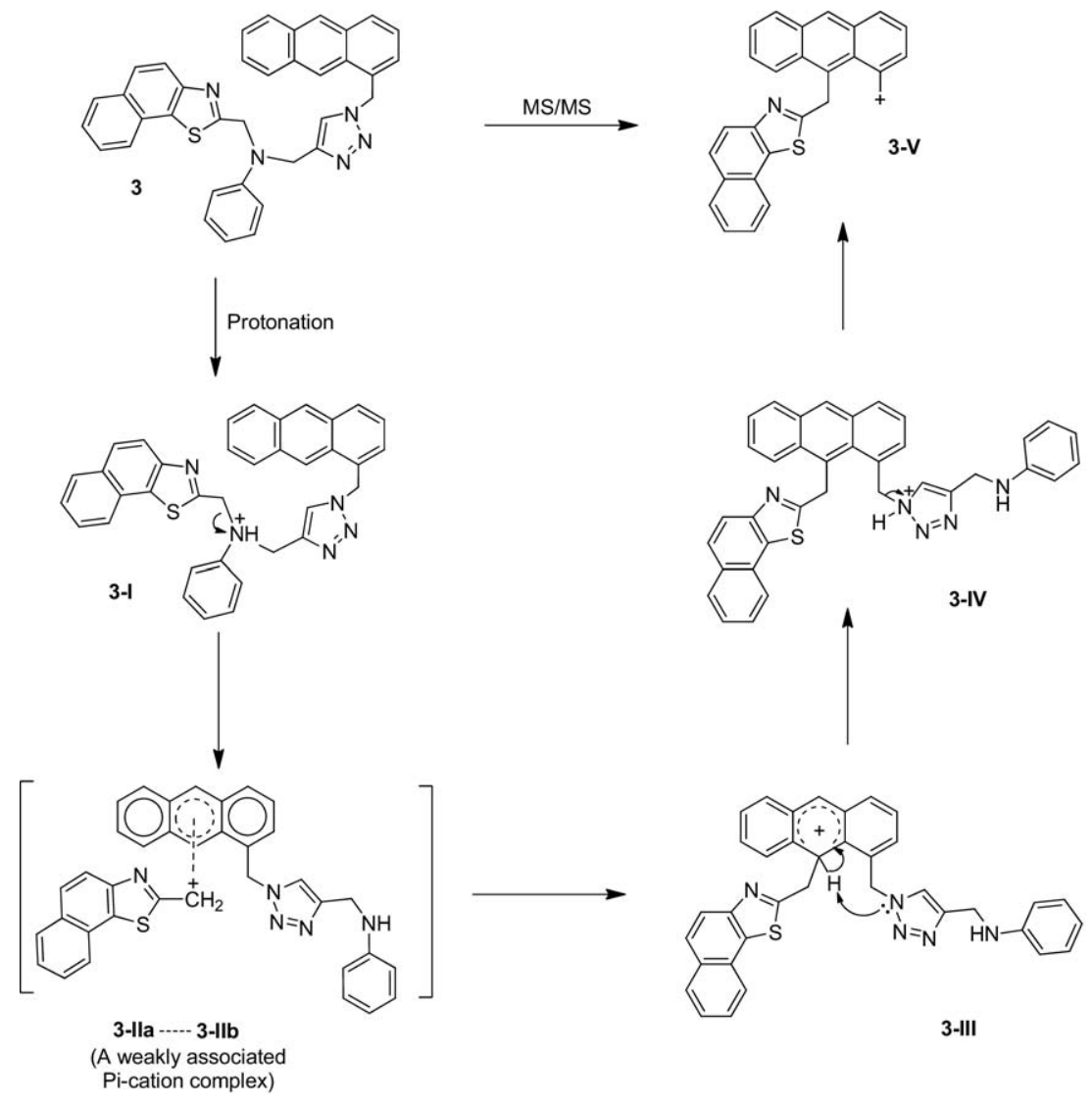

Scheme 3. Proposed rearrangement mechanism of Compound 3.

$\mathrm{kcal} / \mathrm{mol}$ ) were also calculated using an isodesmic equation (Eq. 1) on the B3LYP/6-31G* optimized geometries using Spartan'06. The greater the value of stabilization energy, the more stable the carbocation will be [23]. The calculated stabilization energies also are consistent with the results observed in MS/MS, suggesting higher stabilization energy for Compound $\mathbf{3}$ and lower stabilization energy for Compound 4 . In contrast, to further support the crucial role of the carbocation in the rearrangement reaction, Compounds 9 and 10, which have the same structure as Compound 3 except the substitutes (propyl group for Compound 9 and butyl group for Compound 10) linked to tertiary amine, were synthesized and analyzed by ES-MS/MS. It is impossible for them to form 3-IIa-like stable carbocations following the pathway shown in Scheme 3. As expected, no rearrangement ions were detected in the MS/MS for Compounds 9 and 10. The results from these experiments and calculations confirm that the rearrangement reaction is likely a result of generating a carbocation. Moreover, there was a greater likelihood to observe a rearrangement ion with a more stable carbocation.

With respect to the substitution position, there are some possible positions on the anthracene moiety such

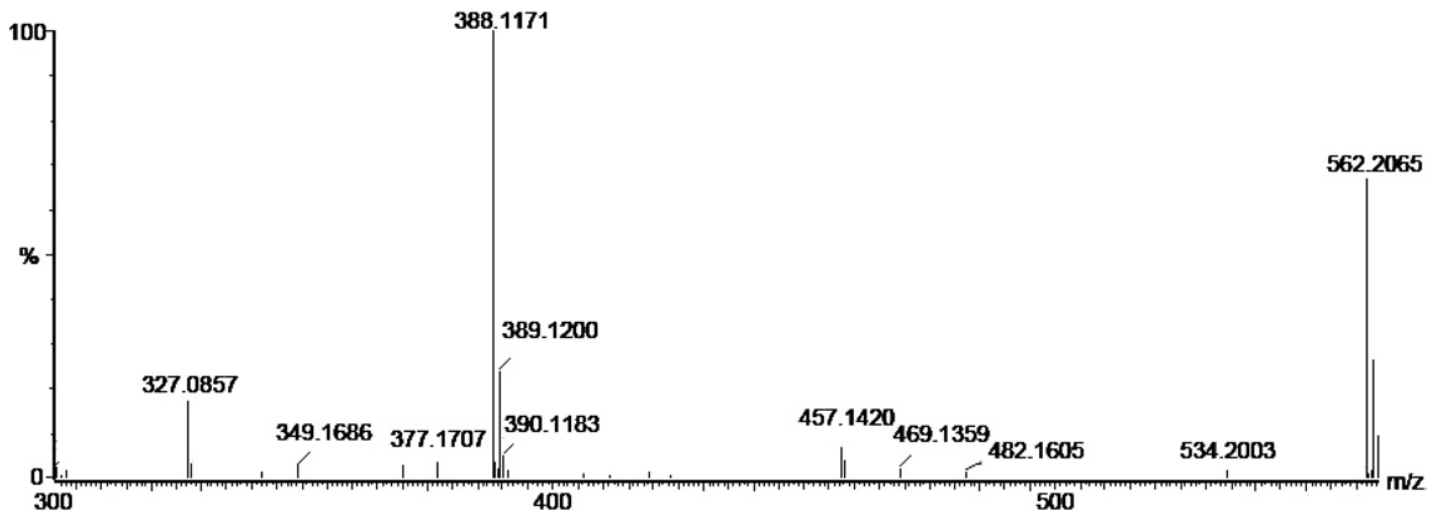

Figure 2. High resolution MS/MS spectrum of Compound $3[\mathrm{M}+\mathrm{H}]^{+}$. 


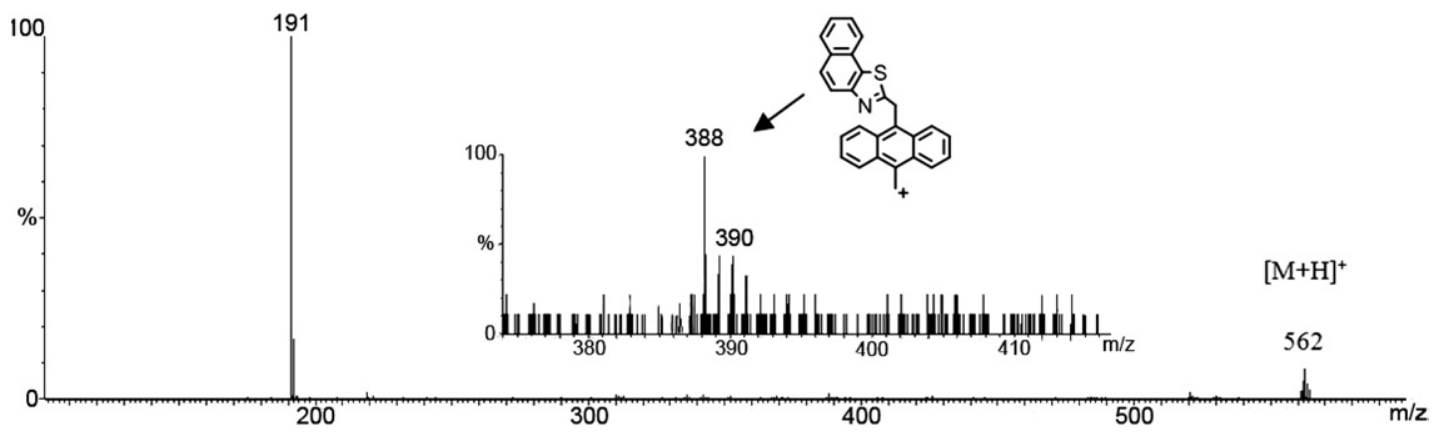

Figure 3. MS/MS spectrum of Compound 11.

as $\alpha, \beta$, and $\gamma$ for an electrophilic attack by the carbocation. However, the $\gamma$ positions of anthracene are in general more reactive towards an electrophilic attack. When Compound $\mathbf{1 1}$ from azide $\mathbf{Z 2}$ and alkyne A3 with an azide group at the $\gamma$ position was synthesized and analyzed by ESI-MS/MS, a rearrangement ion was detected with a very low abundance since only one $\gamma$ position is available (Figure 3). Additional experiments were carried out with Compound 12, which has both $\gamma$ positions occupied. As predicted, no rearrangement ion was detected in MS/MS. It implies that the carbocation can only attack the $\gamma$ positions of the anthracene moiety. To confirm this, the 3-IIb in the rearrangement mechanism (Scheme 3) was modeled at the DFT B3LYP level of theory with a $6-31 \mathrm{G}^{*}$ basis set (Figure 4). Mulliken charge population analysis shows that $\mathrm{C} 6$ has the negative charge $(-0.322)$. C9 has a smaller negative value $(-0.300)$ than $\mathrm{C} 6$ but a much larger negative value than the other carbons. The greater the negative charge on the atom, the more likely an electrophilic attack will occur on that atom [25]. Beside Mulliken charge population analysis, the condensed Fukui index values were obtained from condensed Fukui function equation (Eq. 2) [26]. The

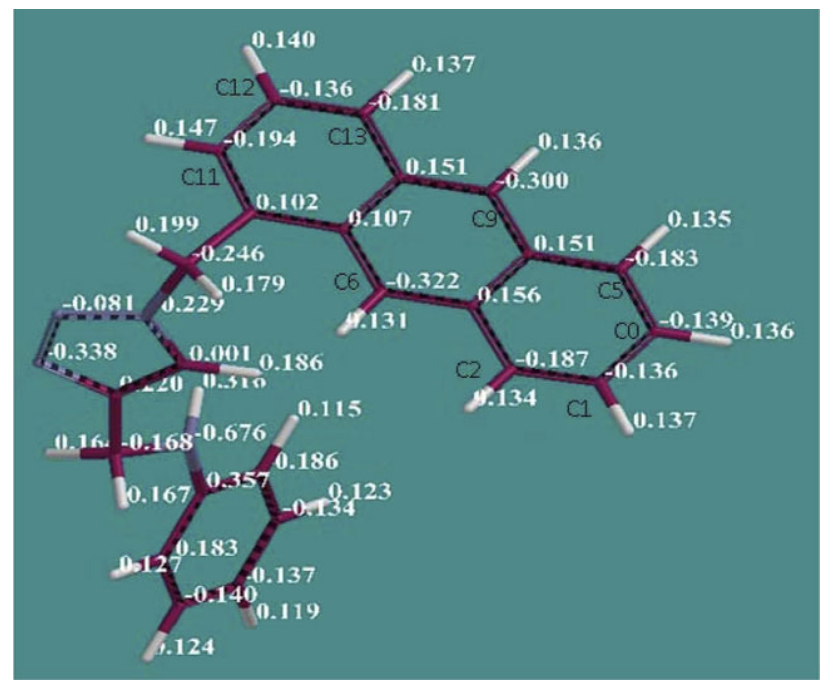

Figure 4. Optimized geometry of 3-IIb derived from Compound 3 and Mulliken charge on hydrogen atom (positive value) and Mulliken charge on carbon (negative value) at DFT B3LYP/6-31G* (Spartan'06). calculated results show that the $\mathrm{C} 6$ at the $\gamma$ position of the anthracene moiety has the largest condensed Fukui index value (0.037). C9 at the opposite $\gamma$ position of the anthracene moiety has a smaller value $(0.025)$ than $\mathrm{C} 6$ but greater than other carbons at the $\alpha$ or $\beta$ positions (Table 4). This means that the C6 atom should be the most reactive site towards an electrophilic attack of carbocation. Fukui index and Mulliken charge values for 3-IIb suggest that C6 could be most susceptible and C9 could have less chance than C6 but more opportunity than other carbons at $\alpha$ or $\beta$ positions to electrophilic reaction. The calculated results are consistent with the MS/MS data, thereby supporting the proposed theory that the carbocation attacks the $\gamma$ position of the anthracene moiety.

$$
\mathrm{fc}=\mathrm{qc}(\mathrm{N})-\mathrm{qc}(\mathrm{N}-1)
$$

\section{Conclusions}

The triazolo-anthracene derivatives as fluorescent inhibitor analogues were investigated by ESI-MS/MS, and the fragmentation pathways have been characterized. These pathways involve the cleavage on $\mathrm{C}-\mathrm{N}$ bonds on both sides of the protonated tertiary amine and the cleavage of the $\mathrm{C}-\mathrm{N}$ bond between the anthracene and triazole moieties leading to base peak. Besides direct cleavages, a rearrangement ion at $\mathrm{m} / \mathrm{z} 388$ in ESI-MS/MS was observed, and a possible rearrangement mechanism is proposed that involves a carbocation migration from the amine group to the $\gamma$ position

Table 4. Condensed Fukui index and Mulliken charge of intermediate 3-IIb

\begin{tabular}{ccc}
\hline Condensed & Fukui index & Mulliken charge \\
\hline \hline C0 & 0.009 & -0.139 \\
C1 & 0.01 & -0.136 \\
C2 & 0.002 & -0.187 \\
C5 & 0.009 & -0.183 \\
C6 & 0.037 & -0.322 \\
C9 & 0.025 & -0.300 \\
C11 & 0.019 & -0.194 \\
C12 & 0.00 & -0.136 \\
C13 & 0.01 & -0.181 \\
\hline
\end{tabular}


on the anthracene moiety. A number of control experiments, high-resolution mass spectrometry, and theoretical calculations support the proposed mechanism. Investigation of the rearrangement mechanism indicates that it is essential for the rearrangement reaction to form a relatively stable carbocation and to have a free $\gamma$ position on the anthracene.

\section{Acknowledgments}

The authors acknowledge partial support for this work by the Nanocenter of University of South Carolina, South Carolina EPSCoR/CRP program, the Alfred P. Sloan Scholarship, and the Camille Dreyfus Teacher Scholar Award. The hTS samples were kindly supplied by Dr. Lukasz Lebioda.

\section{References}

1. Benepal, T. S.; Judson, I. Z. D. 9331: Discovery to Clinical Development. Anticancer Drugs 2005, 16, 1-9.

2. Speers, A. E.; Adam, G. C.; Cravatt, B. F. Activity-Based Protein Profiling In vivo Using a Copper(I)-Catalyzed Azide-Aalkyne [3 + 2] Aycloaddition. J. Am. Chem. Soc. 2003, 125, 4686-4687.

3. Xie, F.; Sivakumar, K.; Zeng, Q.; Bruckman, M. A.; Hodges, B.; Wang, Q. A Fluorogenic 'Click' Reaction of Azido-Anthracene Derivatives. Tetrahedron 2008, 64, 2906-2914.

4. Kolb, H. C.; Finn, M. G.; Sharpless, K. B. Click Chemistry: Diverse Chemical Function from a Few Good Reactions. Angew. Chem. Int. Ed. 2001, 40, 2004-2021.

5. Berger, S. H.; Berger, F. G.; Lebioda, L. Effects of Ligand Binding and Conformational Switching on Intracellular Stability of Human Thymidylate Synthase. Biochim. Biophys. Acta Prot. Proteom. 2004, 1696, 15-22.

6. Wang, Q.; Chan, T. R.; Hilgraf, R.; Fokin, V. V.; Sharpless, K. B.; Finn, M. G. Bioconjugation by Copper(I)-Catalyzed Azide-Alkyne $[3+2]$ Cycloaddition. J. Am. Chem. Soc. 2003, 125, 3192-3193.

7. Sawa, M.; Hsu, T.-L.; Itoh, T.; Sugiyama, M.; Hanson, S. R.; Vogt, P. K.; Wong, C.-H. Glycoproteomic Probes for Fluorescent Imaging of Fucosylated Glycans In Vivo. Proc. Nat. Acad. Sci. U.S.A. 2006, 103, 1237112376.

8. Sivakumar, K.; Xie, F.; Cash, B. M.; Long, S.; Barnhill, H. N.; Wang, Q. A Fluorogenic 1,3-Dipolar Cycloaddition Reaction of 3-Azidocoumarins and Acetylenes. Org. Lett. 2004, 6, 4603-4606.

9. Beatty, K. E.; Xie, F.; Wang, Q.; Tirrell, D. A. Selective Dye-Labeling of Newly Synthesized Proteins in Bacterial Cells. J. Am. Chem. Soc. 2005, 127, 14150-14151

10. Beatty, K. E.; Liu, J. C.; Xie, F.; Dieterich, D. C.; Schuman, E. M.; Wang, Q.; Tirrell, D. A. Fluorescence Visualization of Newly Synthesized Proteins in Mammalian Cells. Angew. Chem. Int. Ed. 2006, 45, 7364-7367.
11. Hsieh, Y. S.; Korfmacher, W. The Role of Hyphenated ChromatographyMass Spectrometry Techniques in Exploratory Drug Metabolism and Pharmacokinetics. Curr. Pharmaceut. Des. 2009, 15, 2251-2261.

12. Jonsson, A. P. Mass Spectrometry for Protein and Peptide Characterization. J. Cell. Mol. Life Sci. 2001, 56, 868-884.

13. Wells, J. M.; McLuckey, S. A. Collision-Induced Dissociation (CID) of Peptides and Proteins. Methods Enzymol. 2005, 402, 148-85.

14. Chen, Y.; Yin, Y.; Sun, X.; Liu, X.; Wang, H.; Zhao, Y. A Novel Rearrangement in Electrospray Ionization Multistage Tandem Mass Spectrometry of Amino Acid Ester Cyclohexyl Phosphoramidates of AZT. J. Mass Spectrom. 2005, 40, 636-641.

15. Ju, Z Y. Ye Y · Zhong S. B · Zou, RY · Liao, XC : Zhao, Y A Novel Rearrangement in ESI-MS ${ }^{n}$ of Spirocyclic Pentaerythritol Di(Phosphate Monoamides). Int. J. Mass Spectrom. 2008, 273, 31-34.

16. Chen, J.; Chen, Y.; Niu, Y.-L.; Fu, H.; Zhao, Y.-F. A Carbonyl Oxygen Migration in Electrospray Ionization Mass Spectrometry and Its Application in Differentiating a- and b-Alanyl Peptides. J. Mass Spectrom. 2002, 37, 934-939.

17. Wang, H.-Y.; Guo, Y.-L.; Lu, L. Studies of Rearrangement Reactions of Protonated and Lithium Cationized 2-Pyrimidinyloxy-N-Arylbenzylamine Derivatives by MALDI-FT-ICR Mass Spectrometry. J. Am. Soc. Mass Spectrom. 2004, 15, 1820-1832.

18. Sun, M.; Dai, W.; Liu, D. Q. Fragmentation of Aromatic Sulfonamides in Electrospray Ionization Mass Spectrometry: Elimination of SO2 Via Rearrangement. J. Mass Spectrom. 2008, 43, 383-393.

19. Savitski, M. M.; Kjeldsen, F.; Nielsen, M. L.; Zubarev, R. A. Hydrogen Rearrangement to and from Radical z Fragments in Electron Capture Dissociation of Peptides. J. Am. Soc. Mass Spectrom. 2007, 18, 113-120.

20. Olah, G. A.; Mathew, T.; Goeppert, A.; Rasul, G.; Prakash, G. K. S.; Esteves, P. M. Carbocationic Rearrangement of Pivaloyl Cation and Protonated Pivalaldehyde in Superacid Medium: A Novel Solution Equivalent of the McLafferty Rearrangement. J. Am. Soc. Mass Spectrom. 2004, 15, 959-965.

21. Chang, K.-C.; Su, I.-H.; Senthilvelan, A.; Chung, W.-S. Triazole-Modified Calix[4]crown as a Novel Fluorescent On-Off Switchable Chemosensor. Org. Lett. 2007, 9, 3363-3366.

22. Rawat, D. S. Benites, P. J. Incarvito, C. D. Rheingold, A. L. Zaleski, J. M. The Contribution of Ligand Flexibility to Metal Center Geometry Modulated Thermal Cyclization of Conjugated Pyridine and Quinoline Metalloenediynes of Copper(I) and Copper(II). Inorg. Chem. 2001, 40, 1846-1857.

23. Baik, W.; Yoon, C. H.; Koo, S.; Kim, B. H. A Computational Investigation of the Stability of Cyclopropyl Carbenes. Bull. Korean Chem. Soc. 2004, 25, 90-96.

24. Santos, L. S.; Padilha, M. C.; Radler. de Aquino Neto, F.; Pereira, A. d S.; Menegatti, R.; Fraga, C. A. M.; Barreiro, E. J.; Eberlin, M. N. Electrospray Ionization Mass and Tandem Mass Spectra of a Series of N-Pyrazolylmethyl and N-Triazolylmethyl N-Phenylpiperazines: New Dopaminergic Ligands with Potential Antipsychotic Properties. J. Mass Spectrom. 2005, 40, 815-820.

25. Aušra, V.; Gytis, V.; Jiri, S. Theoretical Study of Benzo-fused Thieno[3,2b]Furans in the Reactions with Electrophiles. Proceedings of the 11th International Electronic Conference on Synthetic Organic Chemistry (ECSOC-11); Galicia, Spain, 2007, p. 1-14.

26. Yang, W.; Mortier, W. The Use of Global and Local Molecular Parameters for the Analysis of the Gas-Phase Basicity of Amines. J. Am. Chem Soc. 1986, 108, 5708-5711. 